Kolosok Tetiana. Phenomenon of Women Religiousness from the View Point of Religion Sociology. Modern woman has freedom of choice of spiritual self-realization ways, both within the framework of traditional religions and neo-religious movements. Growing activity of women in the religion sphere and search of spiritual self-realization actualizes the selected research subject. The aim of the article is to analyze phenomenon of woman religiousness, its reasons from view point of religion sociology. It is established in the article that the level of religious activity of women grew. It worth taking into account that religiousness is not limited to church activity, that is why research of religion should take into account faith and supernaturalism that is out of the organized church organization.

Conclusions concerning the higher religiousness of women are drawn on the basis of quantitative methods of sociological analysis. The Ukrainian researchers N. Dudar, B. Melnyk, M. Parashchevin, S. Salnikova, studying the religiousness of Ukrainian society assert that women are more religious than men (75\% against $57 \%$ in 2013 ). Researchers consider that such state can be explained by psycho-physiological and mental features of different sexes representatives.

It is marked in the article, that the numerous sociological researches conducted in various state formations confirm the thesis about women's high religiousness. It is found out by the author, that presently within the framework of religion sociology theoretical approaches that explain differences in the religiousness of men and women are turned out: economic theories, Marxist theory and psycho-social theories. Attempts to check these theories in empiric way have not brought unambiguous conclusions or have not been successful.

Key words: religiosity, religion sociology, phenomenon of woman religiousness.

Статтю отримано 12.03.2015 p.

УДК 316.334.22-053.81

Екатерина Чучилина

\title{
«Молодой специалист» как категория современного социологического анализа
}

В рамках статьи рассмотрены различные подходы к определению «молодого специалиста» с точки зрения профессиональных, социальных и профессионально-трудовых характеристик, новые тенденции в современных практиках, законодательная база. Уточняется понятие «молодого специалиста» как студента или выпускника любого профессионального учебного заведения, приступающего к профессиональной деятельности по полученной специальности и обладающего практическим опытом и стажем работы по выбранной специальности не более одного года.

Ключевые слова: молодой специалист, рынок труда, карьера, профессиональная социализация.

Постановка научной проблемы и ее значение. Современное общество находится в перманентном трансформационном состоянии. Накладывающиеся друг на друга события дают такие образцы изменений, которые формируют новые модели поведения социальных субъектов, задают рамки и векторы их жизнедеятельности.

Молодые специалисты как реальный и перспективный трудовой ресурс общества при этом сталкиваются с целым рядом традиционных и инновационных факторов, которые трансформируют модели их поведения.

В современных условиях движения украинского общества к инновационности важным видится раскрытие потенциала молодых специалистов как ресурса будущего, возможностей использования их знаний, умений и компетенций для инновационного преобразования современных организаций, для их максимальной эффективности в условиях глобализации и динамичного рождения новых технологических решений.

При этом сама категория «молодой специалист» остается не до конца разработанной с точки зрения социологической науки: в современном социальном поле в большей мере востребована нормативная трактовка данного понятия, которая определяет те или иные правила регулирования отношений молодых специалистов со сферами социума. Тем не менее, общество изменяется достаточно динамично, а это требует уточнения категориального ряда, его описывающего.

Анализ исследований по этой проблеме. Традиция изучения молодых специалистов в

(C) Чучилина E., 2015 
отечественной социологии восходит к научной школе Е. А. Якубы, в рамках которой выделены основные характеристики молодых специалистов и осуществлено исследование их социальной активности. На сегодня актуализировались попытки уточнения сущности категории «молодой специалист», которые предпринимаются такими отечественными и российскими учеными, как Е. Бавыкина, И. Вирина, В. Жиркова, А. Чернышева и др. Данные исследовательские поиски направлены, прежде всего, на адаптацию и усовершенствование критериальных основ определения молодых специалистов в современных условиях. Тем не менее, на сегодня не существует единого понимания молодых специалистов как в научной, так и в практической плоскости их изучения, что и определило проблематику нашего исследования.

Цель статьи - на основе анализа существующих определений молодых специалистов и новых тенденций в социальных практиках уточнить определение понятия «молодой специалист». Для этого обратимся к смысловым нагрузкам этого понятия и основным характеристикам представителей данной группы.

Изложение основного материала и обоснование полученых результатов исследования. Как показывает анализ литературы, существуют небольшие вариации в определении молодых специалистов. В толковом словаре Ожегова под молодым специалистом понимается «выпускник вуза или техникума, начинающий самостоятельную работу» [6].

В такой наиболее общей трактовке критериями принадлежности к категории молодых специалистов выступают факт выпуска из профессионального учебного заведения и факт начала трудовой деятельности.

В специализированных исследованиях данной сферы указанные выше критерии получили дальнейшее развитие. Например, А. Чернышева определяет молодого специалиста как «выпускника любого профессионального учебного заведения, проработавшего по выбранной специальности не более трех лет или не имеющего такого опыта» $[12$, с. 23]. Очевидно, что в таком определении критерий «начало трудовой деятельности» конкретизируется через опыт работы по специальности.

Иные уточняющие определения можно встретить и у других авторов. Например, «молодой специалист - это сотрудник в возрасте до 35 лет, получивший среднее или высшее профессиональное очное образование и устроившийся на работу по специальности в течение года после получения диплома» [5].

Данный подход помещает категорию молодых специалистов в рамки социально-демографической группы молодежи, что дополняет критериальный ряд в определении молодых специалистов, а также уточняет тот момент, что работа, к которой приступает молодой специалист, должна соответствовать специальности, и найти ее необходимо в течение года после получения среднего или высшего профессионального очного образования. То есть в таком критериальном ряду связка «специальность работа» является обязательной (о чем не всегда упоминается в других определениях), так же, как и принадлежность к социально-демографической группе «молодежь».

По мнению Е. Н. Бавыкиной, «молодой специалист - это трудоустроенный по специальности в течение 1 года после окончания учебного заведения индивид в возрасте от 18 до 30 лет со средним специальным или высшим профессиональным образованием (в том числе неоконченным) и трудовым стажем по специальности не более 3 -х лет» [2, с. 30].

Такой подход несколько расширяет образовательные рамки критериев отнесения к молодым специалистам, однако характеризуется дискуссионностью предложенных критериев. Более того, данный подход к трактовке молодого специалиста, на наш взгляд, не в полной мере отвечает реальностям современного рынка труда и формально привязан к определенному квалификационному уровню, что мешает его гибкости в применении.

В отечественной социологии традиция исследования молодых специалистов восходит к научной школе Е. А. Якубы [10]. Она определяет молодого специалиста как выпускника вуза, который приступает к трудовой деятельности и находится на стадии жизненного самоопределения в карьере.

В таком подходе очевиден акцент на трех основных моментах, которые могут являться отправными точками при анализе молодого специалиста: наличие высшего образования; начало трудовой деятельности; нахождение на стадии жизненного самоопределения в карьере. Данные критерии составили основу разработки различных концептуальных позиций относительно молодых специалистов. Однако современные реалии требуют их более пристального анализа. 
Первый критерий (наличие высшего образования) в современных условиях теряет свою принципиальную значимость в силу частого прихода в практическую профессиональную деятельность студентов старших курсов. Как показывают исследования ${ }^{1}$, постоянно подрабатывают 12,3 \% студентов, а время от времени - 38,5\%. Более того, эта подработка полностью или частично связана с получаемой специальностью в $51,2 \%$ случаев (или $28,2 \%$ от всех студентов). Мотивация подработки различная, но мотивы, прямо или косвенно связанные с профессиональным развитием - самореализация - 15,4 \%, конструирование социально-профессиональных сетей - 7,3 \%, испытание себя в будущей профессии 6,5 \% (в трети случаев указывают на профессиональные интересы).

Второй критерий (начало трудовой деятельности) видится нам универсальным и реально работающим.

Третий (нахождение на стадии жизненного определения в карьере) несет в себе глубокую содержательную нагрузку: наполняет смыслом трудовую деятельность, к которой приступает молодой человек, помещает ее в разряд терминальных ценностей.

Очевидно, что среди научного сообщества в целом нет единого мнения в определении понятия «молодой специалист», так же как и о количестве и содержании критериев отнесения работников к этой категории. «Ученые по-разному характеризуют часть общества, относящуюся к рассматриваемой категории, определяя ее как “выпускники”, “люди”, “лица”, “сотрудники”, и накладывая тем самым различные условия и ограничения на возможность присвоение статуса "молодого специалиста" индивиду и срокам ею действия. В научных работах по-разному определены и возрастные границы “молодого специалиста", выделен различный стажевой ценз, ограничивающий принадлежность работника к данной категории» [4, с. 175].

Некоторую определенность этой дискуссии может придать нормативно-законодательная база. Например, пункт 4 ст. 7 Закона «О содействии социальному становлению и развитию молодежи в Украине» определяет молодых специалистов как и часть вторая ст. 197 КЗоТ: «К молодым специалистам относятся выпускники государственных высших учебных заведений и профессионально-технических училищ, потребность в которых определена государственным заказом» [8].

Как показал анализ, большинство нормативных определений молодого специалиста (например [7; 8]) распространяется на выпускников государственных высших учебных и профессиональных учебновоспитательных заведений, которые были заказаны предприятиями, учреждениями, организациями и направлены на работу в соответствии с установленным порядком. В результате, в нормативнозаконодательном плане базовыми критериями молодого специалиста являются уровень образования, стаж работы до 3-х лет и наличие направления/заказа на подготовку. Данный подход, по-видимому, выполняет свою основную - регулирующую - функцию. Однако в рамках социологического познания он имеет ограниченные возможности использования. Это связано с расширением временных рамок трудоустройства молодых специалистов (в том числе и по специальности) за счет работы на старших курсах. Ведь современный работодатель заинтересован в снижении риска при принятии на работу, особенно выпускников. Поэтому сами вузы и их выпускники реализуют программы, позволяющие накопить максимальный ресурс, обеспечивающий им успешное трудоустройство, а работодателю качественного сотрудника. Поэтому в последнее время к вышеуказанным категориям причисляют и студентов четвертых-пятых курсов (см., например, [3, с. 21]).

Наряду с нормативно-законодательными акцентами в рассмотрении молодых специалистов, важным видится анализ социальных практик по их идентификации. Как отмечают исследователи, «в одних организациях к молодым специалистам сегодня относят работников не старше 30 лет, в других 35 лет, в одних к специалистам относят молодого работника со средним специальным образованием, в других - с высшим, в третьих - и тех, и других. В ряде организаций наличие специального образования как критерий отнесения к категории «специалист» может быть подтвержден не только соответствующим дипломом, но и фактом обучения на последних курсах специалитета (в одних организациях) и/или магистратуры (в других организациях), в связи с чем необходимость быть трудоустроенным по специальности в течение одного года после окончания обучения как критерий отнесения работника к рассматриваемой категории представляется неэффективным. В ряде организаций для отнесения

\footnotetext{
${ }^{1}$ Опрос студентов Украины, проведенный под руководством д-ра ист. наук, проф. В. И. Астаховой $(\mathrm{n}=2775,2009)$.
} 
работника к молодым специалистам ограничивают имеющийся у него опыт предыдущей работы (1,53 года) и период времени, на который данный статус работник получает» [4, с. 176].

Проанализированный материал по теоретическим, нормативно-правовым и практическим подходам к пониманию молодых специалистов позволяет вычленить базовые признаки рассматриваемой категории трудовых ресурсов, актуальные в современных условиях. В качестве основных признаков категории «молодой специалист» можно выделить наличие профессионального образования (или завершение процесса его получения), трудоустройство по полученной (получаемой) специальности, трудовой стаж по профилю трудоустройства. Используя их и обобщая разные подходы, мы считаем, что молодой специалист - это студент или выпускник любого профессионального учебного заведения, приступающий к профессиональной деятельности по полученной специальности и обладающий практическим опытом и стажем работы по выбранной специальности не более одного года.

Научный анализ молодых специалистов предполагает обращение к их характеристикам, которые мы предлагаем подразделять на три группы: психологические, социальные, профессионально-трудовые.

Первая группа определяется, прежде всего, возрастными особенностями молодых специалистов. Статусная категория «молодой специалист», как отмечает Е. Бавыкина, «по содержанию может варьироваться от 18 до 30 лет. В этот период работник осваивает профессию, приобретает необходимые навыки, формируется его квалификация, происходит самоутверждение и появляется потребность к установлению независимости. Его продолжает беспокоить безопасность существования, забота о здоровье. Обычно в этом возрасте создаются и формируются семьи, поэтому появляется желание получать заработную плату, уровень которой выше прожиточного минимума» [1, c. 30].

Можно говорить, что этому возрастному периоду присущи определенные психологические образования: формируется социальная ответственность и готовность вхождения в новые социальные общности; «примериваются» различные социальные роли и обретается личностная идентичность; развивается рефлексия, теоретизирование, идеализация; актуализируется способность различать противоречия в словах, действиях, поступках; молодые люди стремятся к самореализации и индивидуализации (М. Дзугкоева); решающим условием быстрой адаптации к условиям труда, дальнейшего профессионального совершенствования и повышения квалификации становится профессиональная готовность (М. Дьяченко, Л. Кандыбович, В. Лукина); достигается социальная зрелость, что предполагает возможность выполнения социальных обязанностей и принятие на себя ответственности за свою жизнь; «субъективно достижение социальной зрелости переживается появлением у молодого человека чувства взрослости» (О. Хухлаева) [11].

К этой группе особенностей молодых специалистов можно отнести и возрастные кризисы, связанные, прежде всего, со вступлением в самостоятельную жизнь [9]. Кризисность возраста может проявляться в резкой смене жизненных планов, в разочаровании правильности выбора специальности, в расхождении представлений об условиях и содержании профессиональной деятельности и ее реальном протекании. Центральной проблемой становится нахождение молодым человеком индивидуального отношения к культуре, к социальной реальности; определение своего собственного взгляда на жизнь.

Рассмотренная группа характеристик молодых специалистов тесно связана со второй группой социальные характеристики. В ней системообразующей выступает социальная зрелость молодого специалиста. Социальная зрелость - социально и психологически обусловленный этап развития личности, который характеризуется обретением человеком свойств самостоятельности и самодостаточности. Как отмечает Е. Якуба, социальная зрелость представляет собой уровень психологической готовности и реальной подготовленности молодого специалиста к выполнению разнообразных социальных функций [10]. Социально зрелый человек способен не только осознавать собственные экономические и гражданские права и обязанности, не только эффективно усваивать групповые и общественные нормы, но также критически относиться к наличному положению дел в социуме.

Достижение социальной зрелости выступает непрерывным и достаточно продолжительным во времени процессом, иногда сопровождающимся чередой социально-нравственных выборов. Изучение проблем становления социальной зрелости молодых специалистов показывает, что среди них неготовность принять ответственность за свою жизнь, выполнять социальные обязанности; неразвитость способности к преодолению жизненных проблем, осложняющих достижение избранной цели; слабая сформированность навыков самоорганизации, анализа ситуации, чувства ответственности, личной дисциплины и др. 
Для преодоления этих проблемных зон следует развивать личностные качества, которые обеспечивают жизненное самоопределение, способность к самореализации, обусловливают конкурентоспособность молодого специалиста и дают определенные гарантии его успешности не только в предстоящей профессиональной деятельности, но и в целом в жизни: стремление к самосовершенствованию, мобильность, мотивация к достижению успеха, быстрая адаптация к условиям труда, способность работать в группе, инициативность и любознательность и др.

Наряду с социальной зрелостью важной социальной характеристикой молодых специалистов выступает их социально-экономическое положение. При этом выделяют его качественные и количественные показатели. Качественный показатель характеризует положение молодого специалиста в соответствии с экономически привлекательной для него позицией, количественный - с точки зрения численного показателя спроса на предоставляемые молодыми специалистами услуги.

С увеличением потребности молодежи и ее заинтересованности в поиске рабочего места, процесса осуществления деятельности вне зависимости от полученной специальности социально-экономический статус молодого специалиста может повышаться и понижаться, поскольку не всегда полученная работа гарантирует смену социального, тем более - экономического статуса. Здесь необходимо иметь в виду, что повышение социального статуса допускает возможность повышения экономического показателя заработной платы молодого специалиста, не исключает возможность понижения экономического показателя его заработной платы; а понижение социального статуса не означает понижение экономического эквивалента заработной платы молодого специалиста, но допускает понижение его экономического положения.

В условиях глобализации и трансформации современного общества актуален вопрос о состоянии профессиональной ориентации молодого специалиста, тем более что ее закрепление осуществляется уже в процессе обучения, уровень которого в последующем отражает проекцию на профессиональное поведение молодого специалиста.

Это обращает нас к третьей группе выделенных нами характеристик - профессионально-трудовой. В ее рамках, в первую очередь, выделяются вопросы назначения и сущности профессии, ее культурной и общественной ценности, профессиональных норм, способов самоопределения.

В профессионально-трудовом плане молодых специалистов необходимо рассматривать как отдельную категорию трудовых ресурсов, которую отличают от других групп следующие особенности, в основном связанные с их трудовой деятельностью: стратегическая категория, уязвима при трудоустройстве и трудно и долгоадаптируемая, но при этом более мобильная, иногда менее мотивирована, ограничена материальными ресурсами ${ }^{1}[4$, с. 176-177].

Данная группа характеристик выступает ключевой в достижении молодыми специалистами профессиональной успешности. А особое место в ней занимает профессиональная социализация. Этот процесс происходит в реальных условиях конкретной социальной системы. Известно, что ведущим фактором в данной связи выступает качество подготовки молодых специалистов, их навыки и компетенции. Важным является и социальная идентификация личности молодого специалиста в новой для него среде, как профессиональной, так и общественной. Рассматривая профессиональную социализацию с точки зрения вхождения молодого специалиста в русло профессиональной деятельности, следует отметить ее фундаментальную функцию, направленную на знакомство, установление и упрочнение профессиональных норм, представлений и правил в профессиональных поведенческих стратегиях молодого специалиста. Данный процесс может рассматриваться и как движение молодого специалиста к статусу профессионала.

\footnotetext{
${ }^{1}$ «Молодые работники являются стратегической категорией трудовых ресурсов страны, в структуре которой наиболее перспективной частью являются молодые работники со специальным образованием; молодые специалисты более уязвимы с точки зрения трудоустройства, чем специалисты старших возрастных групп, поскольку не имеют достаточного практического опыта работы; трудовая адаптация молодых работников на предприятии более сложная, долгая и трудоемкая, чем работников, имеющих трудовой стаж; молодые работники - более мобильная группа персонала, чем работники других возрастных групп; профессиональные ожидания, сформировавшиеся у молодых специалистов в результате обучения, нередко не находят своей реализации в исполнительских работах, которые молодому работнику предлагают работодатели из-за отсутствия у молодых сотрудников нужного опыта работы, что негативно сказывается на их трудовой мотивации и трудовой активности; как правило, молодые работники находятся на низкой ступени материального достатка, обеспечиваемого трудовой деятельностью - существенный разрыв в уровне оплаты труда «зрелого» профессионала (даже с менее качественным профессиональным образованием) и молодого специалиста (который имеет соответствующее образование, но не имеет практического опыта) всегда в пользу первого; начальный период трудовой карьеры молодых работников часто совпадает с периодом изменения семейного статуса, в связи с чем молодым сотрудникам предприятий требуются специфические социальные льготы и услуги, которые менее актуальные для работников предприятия других возрастных групп» [4, с. 176-177].
} 
Выводы и перспективы дальнейших исследований. В целом анализ категории «молодой специалист» показал, что само понимание его сущности сегодня несколько изменяет свои акценты, это открывает дополнительные возможности для его социологического анализа. Молодой специалист сегодня - это студент или выпускник любого профессионального учебного заведения, приступающий к профессиональной деятельности по полученной специальности и обладающий практическим опытом и стажем работы по выбранной специальности не более одного года.

Молодой специалист в научном анализе может быть представлен через систему трех групп характеристик - психологических, социальных и профессионально-трудовых, которые тесным образом взаимосвязаны друг с другом, развиваются параллельно и могут рассматриваться как основные векторы развития успешности молодого специалиста. Данные векторы связаны не только с содержательными элементами, но и с их функционально-статусным наполнением.

\section{Источники и литература}

1. Бавыкина Е. Н. Анализ уровня развития профессиональной карьеры молодых специалистов-экономистов менеджеров (на примере выпускников БТИ АлтГТУ) / Е. Н. Бавыкина, Л. Г. Миляева // Казанская наука. - 2011. № 8. - С. 29-32.

2. Бавыкина Е. Н. Карьерные стратегии молодых специалистов, оказывающие влияние на качество трудовых ресурсов, как одного из факторов экономического роста России / Е. Н. Бавыкина // Мир науки, культуры, образования. - 2012. - Вып. 6. - С. 15-39.

3. Байденко В. Компетенции в профессиональном образовании / В. Байденко // Высшее образование в России. -2004 . - № 11. - С. 21-25.

4. Вирина И. В. Конкурентоспособность молодых специалистов по оценкам руководителей / И. В. Вирина // Соц. политика и социология. - 2007. - № 2. - С. 174-177.

5. Жиркова В. Статус: «молодой специалист» [Электронный ресурс] / В. Жиркова // Наш университет online. - 2010. - Режим доступа : http://nu.s-vfu.ru/topic_week/status-molodoy-spetsialist/

6. Ожегов С. И. Толковый словарь русского языка / С. И. Ожегов. - М. : Оникс, 2009. - 736 с.

7. Порядок працевлаштування випускників професійно-технічних навчальних закладів, підготовка яких проводилася за державним замовленням [Електронний ресурс] : затв. Постановою Каб. Міністрів України від 27 серп. 2010 р. № 784 // Верховна Рада України. - Режим доступу : http://zakon4.rada.gov.ua/laws/show/784-2010$\% \mathrm{D} 0 \% \mathrm{BF}$

8. Про сприяння соціальному становленню та розвитку молоді в Україні : Закон України № 2998 від 5 лют. 1993 р. // Верховна Рада України [Електронний ресурс]. - Режим доступу : http://zakon4.rada.gov.ua/laws/show/299812

9. Слободчиков В. И. Основы психологической антропологии. Психология развития человека: развитие субъективной реальности в онтогенезе / В. И. Слободчиков, Е. И. Исаев. - М. : [б. и.], 2000. - 421 с.

10. Социальная активность специалиста: истоки и механизмы формирования: (социологический анализ) / [под ред. Е. А. Якубы]. - Харьков : Выща шк. ; Изд-во при Харьк. ун-те, 1983. - 216 с.

11. Хухлаева О.В. Особенности психологического здоровья современных студентов / О. В. Хухлаева // Пед. образование и наука. - 2001. - № 1. - С. 37-40.

12. Чернышова А. Высокий старт или Как начать работу молодому специалисту / А. Чернышова // Работа \& зарплата. - 2007. - № 2. - С. 20-25.

\section{References}

1. Bavykina, Ye. N., Milyayeva, L. G. (2011), "Analysis of the level of development of the professional careers of young professionals and economists managers (an example of graduates BTI AltGTU)", Kazan Science, No. 8, Pp. 29-32.

2. Bavykina, Ye. N. (2012), "Career Strategy of young professionals influencing the quality of human resources as a factor of economic growth in Russia”, The world of science, culture, education, Issue 6, Pp. 15-39.

3. Baydenko, V. (2004), "Competence in vocational education", Higher Education in Russia, No. 11, Pp. 21-25.

4. Virina, I. V. (2007), "The competitiveness of young specialists by estimated the executives", Soc. Politics and Sociology, No. 2, Pp. 174-177.

5. Zhyrkova, V. (2010), "Status: «young specialist»", Our university online, http://nu.s-vfu.ru/topic_week/statusmolodoy-spetsialist/

6. Ozhegov, S. I. (2009), “Dictionary of Russian language”, M. : Oniks, 736 p.

7. "The procedure for employment of graduates of vocational schools, training which was held on public order, approved by Cabinet of Ministers of Ukraine, 8/27/2010, No. 784", http://zakon4.rada.gov.ua/laws/show/784-2010$\% \mathrm{D} 0 \% \mathrm{BF}$

8. "On Promotion of Social Formation and Development of Youth in Ukraine: Law of Ukraine No. 2998, 2/05/1993", http://zakon4.rada.gov.ua/laws/show/2998-12 
9. Slobodchikov, V. I, Isaev, E. S. (2000), "Fundamentals of psychological anthropology. Psychology of Human Development: The development of subjective reality in ontogenesis", M., $421 \mathrm{p}$.

10. "Social activity of the specialist: the origins and mechanisms of formation: (sociological analysis)" (1983), ed. by E. A. Yakuba, Kharkov : High School, 216 p.

11. Khukhlaeva, O. V. (2001), "Features of psychological health of today's students", Pedagogical Education and Science, No. 1, Pp. 37-40.

12. Chernyshova, A. (2007), "High start or How to start a young specialist”, Work \& Salary, No. 2, Pp. 20-25.

Чучиліна Катерина. «Молодий фахівець як категорія сучасного соціологічного аналізу. Молоді фахівці як основний інноваційний ресурс розвитку країни викликають особливий інтерес для дослідження. У межах статті розглянуто різні підходи до визначення «молодого фахівця» щодо професійних, соціальних та професійно-трудових характеристик, нових тенденцій у сучасних практиках, законодавчої бази. Уточнено поняття «молодого фахівця», як студента або випускника будь-якого професійного навчального закладу, котрий приступає до професійної діяльності за отриманою спеціальністю й володіє практичним досвідом і стажем роботи за обраною спеціальністю не більше одного року. Аналіз засвідчив, що в сучасному суспільстві визначення зміщує свої акценти та відкриває нові можливості для вивчення молодих фахівців.

Ключові слова: молодий фахівець, ринок праці, кар’єра, професійна соціалізація.

Chuchylina Kateryna. «Young Specialist» as a Category of Modern Sociological Analysis. The concept of «young specialist» as a category of modern sociological analysis in permanently transforming society is analyzed in the article. Author explored different approaches to the definition in terms of professional, social, and professional and labor characteristics. The notion of «young specialist», as a student or graduate of any professional institution, proceed to the professional activity in their specialty, and having practical experience and work experience in the chosen specialty of not more than one year. The analysis showed that in modern society, the definition shifts its focus and opens up new possibilities for the study of young professionals.

Key words: young specialist, labor market, career, professional socialization.

Статья получена 15.06.2015 2.

УДК 316.728: 330.567.22

\section{Ірина Шконда}

\section{Теоретичні підходи до соціологічних досліджень практик споживання}

Вихід процесу споживання за рамки економічної сфери зумовив підвищення уваги до проблем споживання серед представників усіх соціальних наук. Споживання стає ядром соціальної структури, домінуючим соціальним процесом, підкорює складники суспільного відтворення: виробництво, обмін, розподіл, проявляючись у всіх соціокультурних практиках. Споживацькі практики виявляються як елемент повсякденності, що розкриває основні способи соціального існування в межах певної культури та історичної епохи. Вивчення споживацьких практик уможливлює розуміння не лише процесу споживання, але і його суб'єктів, а також процесу взаємодії між ними.

Ключові слова: споживання, практики споживання, споживацька поведінка, культура споживання.

Постановка наукової проблеми та її значення. Необхідність соціологічного аналізу проблеми споживання зумовлена насамперед зміною ролі споживання в процесі відтворення. Споживанню підкорюються виробництво, розподіл, обмін. Процес споживання виходить за межі економіки, набуває все більше символічно-репрезентативних елементів. Споживання займає провідну позицію в соціальних відносинах, що сприяє їх трансформації. Такі зміни феномену споживання привертають увагу не лише з боку західної науки, але й учених на пострадянському просторі.

Вивчення споживання в межах практичної парадигми дає змогу зрозуміти не лише сам процес споживання, але і його суб'єктів, а також процес взаємодії між ними. Споживацька діяльність досліджується як набір практик, які реалізуються актором у межах об'єктивних і суб'єктивних структур, вони завжди чимось обумовлені, від чогось залежать, а їхні умови - суть їхніх же атрибутів, оскільки формують ситуацію, у якій ці практики конструюються, творяться агентом. Тож використання практичної парадигми, яка існує сьогодні як зручна територія міждисциплінарних

(C) Шконда I., 2015 